extreme exactitude of cranial measurements, especially when based, for example, on the cephalic index only, has often led to creating imaginary races among a given people.

These and other wholesome warnings are uttered by $O$. Hovorka Edler von Zderas in the Centralblatt fïr Anthropologie, iii. p. 289, who also points out that there is no need to calculate indices to the first or second decimal, and he also states that in the analysis of a people one should not take account of differences of less than ten units in the index.

As all investigators are well aware, the cephalic index gives no information upon the real form of the skull; this has been well emphasised by Sergi, who has sought to establish a more rational system of skull nomenclature. M. L. Laloy supports (l'Anthropologie, x. p. IO5) Hovorka's general contention, and refers to the clever visual analysis of the inhabitants of Bretagne by Dr. P. Topinard, which was published in the Joumnal of the Anthropological Institute (1897, xxviii. p. 99). In the last number of the Journal (new series, i. p. 329) Dr. Topinard gives the results of the trip which he made to Cornwall last year in order to compare the anthropological types there with those he had previously ascertained in Bretagne. But in our own country Dr. J. Beddoe has long adopted a similar method of investigation, and his acute and trained powers of observation have thrown a flood of light on the problems of the races of Britain. The methods of the doyen of British anthropologists are those of the field naturalist, and there are many who realise that what is generally known as " natural history," is as integral a part of biology as is the most refined laboratory technique. It is well to use one's eyes for other purposes than $\mathrm{fcr}$ reading off scales on instruments.

WAVE OR BILLOW CLOUDS. $A$ SERIES of cloud photographs taken by Mr. Alfred J. Henry, of the United States Weather Bureau, and contributed to the Monthly Weather Revieze for February, is on several grounds specially instructive. It is too frequently the case that photographers content themselves with a single plate of a cloudy sky, which specially recommends itself to their notice by the grouping and arrangement of the vaporous patches. But in this instance we have a succession of pictures of the same clouds, showing their variation during the interval, and, moreover, taken in various azimuths at different stations, so that we get the same formation viewed from different standpoints. We regret that we can only reproduce one of the very admirable pictures that Prof. Henry has secured, It is the first of the series, and shows the typical arrangement of these clouds as they first arrested the attention of the observer. The altitude was probably that of the mean altocumulus level. Occurring as these clouds do at all possible heights above the surface, we are glad to notice that the term wave or billow, following the nomenclature of Helmholtz, is coming into use, since such a description more nearly expresses the character of the formation than do other terms which generally refer to the height alone.

We have here in the cause of the formation of these clouds an instance of the advantage of theoretical investigation over simple observation. The readings of meteorological instruments explain nothing of the origin or behaviour of atmospheric waves. Prof. Henry has recorded for us, with the care that becomes a meteorologist, that the wind was blowing steadily from the north-west with a velocity of twelve miles an hour. Rain had ceased shortly before, and the temperature, which had fallen to $34^{\circ}$ during the night, had risen at the time at which the photograph was taken $\left(8 \mathrm{~h} .25 \mathrm{~m}\right.$. a.m.) to $36^{\circ}$. The direction of the parallel bands when first observed was ap. proximately east and west. Later they took up a position about $\mathrm{N} .80^{\circ} \mathrm{W}$. to $\mathrm{S} .80^{\circ} \mathrm{E}$. In an hour and a half the typical appearance of the billow wave had passed away, leaving the sky about half covered with cirrus and cirro stratus. It is not unimportant to note, however, that the occurrence of similar weather conditions gave rise to a similar formation of clouds (also photographed) some two months later.

This is all that instrumental registration and careful observation can teach us, and possibly the slow onward movement of meteorological science is traceable to the strict adherence we have generally shown to the record of instrumental indications, rather than a confident appeal to theoretical research. But the study of such a cloud formation as that pictured here goes a step beyond the reading of instruments, and places in our hands a powerful means by which to investigate the motion of the atmosphere. It cannot have escaped general notice that this regular arrangement of streaks presents the peculiarity of cover ing a considerable extent of the sky, almost simultaneously. On a comparatively clear sky these strips of cloud are suddenly formed; and on the other hand, a sky uniformly covered can, in a very short space of time, break up and offer the appearance of these billow waves. This sudden origin of parallel streaks finds a complete analogy in the formation of waves over still water, when a slight wind agitates the surface, and it is seen to break into ripples over a considerable area. Von Helmholtz, working on this suggestion, has shown conclusively that these billow waves are due to the existence of air strata of different temperatures moving with different velocities, and are produced at the surfaces of separation of these various strata. Travellers in balloons have confirmed this theory from actual experiment, and have shown that at very various altitudes this peculiar formation is encountered. It may be that the billow clouds are

NO. I 549, vol. 6o]

visible to us only under peculiar circumstances of moisture, but the wave motion in the invisible air is probably a most common phenomenon, and one that plays a large part in determining our weather conditions.

\section{THE PROPOSED MAGNETIC SURVEY OF THE UNITED STATES.1}

THE present superintendent of the Coast and Geodetic Survey, Prof. Henry S. Pritchett, perceiving the need of expansion in the magnetic work of the Survey, has brought about the formation of a separate division, known as the Division of Terrestrial Magnetism of the United States Coast and Geodetic Survey. The chief of this division is to be $\mathrm{Dr}$. L. A. Bauer, who will have full control of all magnetic work, both in the field and in the office.

The following preliminary outline will serve to give some indication of the character and scope of the work it is proposed to carry out with the enlarged opportunities.

SECUlar Variation InVFSTIGATIONS.

The best evidence of the great demand for secular variation data is the fact that, thus far, eight editions of Schott's secular variation paper have been successively issued by the Survey.

1 Abridged from an advance proof of a paper by Dr. L. A. Bauer in Terrestrial Magnetism. 